\title{
Special issue in honor of Matthias Ballauff
}

\section{A passionate wanderer between real and reciprocal space}

\author{
Joachim Dzubiella ${ }^{1}$ - Alexander Wittemann ${ }^{2}$ \\ Published online: 24 June 2020 \\ (C) The Author(s) 2020
}

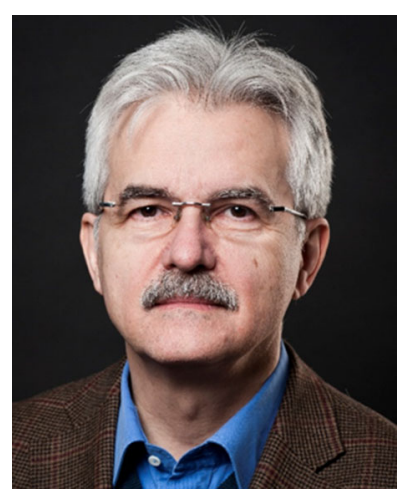

Prof. Dr. Matthias Ballauff

In recognition of his outstanding merits to the national and international colloid and polymer community, Springer Nature is pleased to launch the present special issue of Colloid and Polymer Science dedicated to Prof. Dr. Matthias Ballauff. It has been a true pleasure for us to edit this special issue honoring our friend Matthias.

Bringing together experimental work with theoretical modeling was always a priority for Matthias, which is also reflected in the present special issue in a well-balanced number of experimental and theoretical contributions. When preparing this special issue, we could build on the extensive personal network of collaborators, former co-workers, and

Joachim Dzubiella

joachim.dzubiella@physik.uni-freiburg.de

$\triangle$ Alexander Wittemann

alexander.wittemann@uni-konstanz.de

1 Applied Theoretical Physics-Computational Physics, Physikalisches Institut, Albert-Ludwigs-Universität Freiburg, Hermann-Herder-Str. 3, D-79104 Freiburg, Germany

2 Colloid Chemistry, Department of Chemistry, University of Konstanz, Universitätsstraße 10, D-78464 Konstanz, Germany

friends that Matthias has established and cultivated during his extraordinary career and service for the scientific community. It was therefore an easy task for us to find renowned contributors. It was only with their commitment and the high quality of the research they are sharing with us that put us in the position to compose such a collection of outstanding articles, celebrating and appreciating Matthias' professional career and his enormous contributions to our field.

Last year, Matthias has retired from active professional life. Matthias, born in Cologne in 1952, studied chemistry at the Johannes Gutenberg University in Mainz. In 1981, he obtained his doctorate in physical chemistry with Prof. Bernhard A. Wolf, working on shear degradation of dissolved polystyrene. He then spent 2 years as a postdoc in the group of Prof. Paul J. Flory at the Stanford University. It was there where he began to work on liquid crystalline oligomers and polymers. Matthias then moved back to Mainz, where he became a group leader at the Max Planck Institute for Polymer Research, which was founded shortly before his arrival. There, Matthias was working in the departments of Profs. Gerhard Wegener and Erhard W. Fischer, making important contributions to the liquid-crystalline behavior of stiff-chain polymers bearing flexible side chains.

Soon after completing his habilitation in 1989 , he was appointed as a full professor at the University of Karlsruhe where he headed the Polymer Institute from 1990 to 2003. There, Matthias quickly intensified his passion for the reciprocal space. He obtained plenty of groundbreaking results by extensive use of X-ray and neutron scattering techniques aiming at a comprehensive characterization of polymer nanostructures and colloids. At a time where most scientists considered dendrimers as hollow structures, Matthias together with his colleagues from theoretical physics could verify that dendrimers have their maximum density in the core, which is caused by entropic contributions resulting in back-folding of terminal sites. In addition, colloidal particles, especially those with core-shell morphologies, moved more and more into the center of his research. He explored thermoresponsive 
microgel particles, again by using complementary scattering techniques. Together with his team, he established photoemulsion polymerization as a scalable and flexible route towards well-defined spherical polyelectrolyte brushes. Matthias and his co-workers demonstrated that the latter are ideally suited as carriers for catalytically active nanoparticles, such as enzymes or inorganic nanoparticles.

In 2003, he moved to the University of Bayreuth where he headed the chair of Physical Chemistry I and the Bayreuth Center of Colloids and Interfaces (BZKG). He soon became interested in new analytical techniques that allow for the direct observation of colloids and nanostructures. Cryogenic transmission electron microscopy as a tool to visualize colloids in their native environment became an integral element in his research-without ever losing touch to the beloved reciprocal space. Alloy nanoparticles generated and hosted inside polyelectrolyte brushes and being catalytically active over multiple reaction cycles became an important priority in his research. Parallel to this, he established a rheological laboratory enabling multi-scale investigations of the flow behavior of thermoresponsive microgels. Matthias contributed substantially to making Bayreuth an excellent place for polymer and colloid research in Germany. Together with Prof. Josef Breu, he initialized and launched the Collaborative Research Center (SFB) 840 ("From particulate nanosystems to mesotechnology"). In addition to his scientific achievements, Matthias maintained various successful partnerships with industry.

In the year 2009, Matthias joined the Helmholtz-Zentrum Berlin, where he founded and headed the Institute of Soft Matter and Functional Materials, while affiliated also as a professor to the Department of Physics of the HumboldtUniversität zu Berlin. With his unique familiarity in exploring small scales in reciprocal space - and now being in a largescale facility research environment-he quickly became a central and creative figure in the Berlin scientific network. He established plenty of cooperations, connecting universities, research institutes, as well as industry and the Charité. The newly created synergies led to groundbreaking publications, in many cases jointly with theory, in the fields of colloidal catalysis, protein-polyelectrolyte complexation, and hydrogel-based medical carrier systems. Finally, taking advantage of the laboratory infrastructure in Berlin, Matthias and colleagues established a long-term visionary research program at the HZB for the in-operando study of next-generation electrochemical storage systems for the next years to come.

After his retirement in September 2019, Matthias became a guest professor at the Freie Universität Berlin and can thus finally indulge fully in his passion of solution thermodynamics and the (digital) teaching thereof.

$>$
Matthias Ballauff is the author of more than 400 research articles and reviews in peer-reviewed journals. His publications received more than 12,000 citations $(h$-index $=73)$. In 2015, the German Colloid Society honored Matthias' scientific research in the area of pure and applied colloid science by the Ostwald Prize. In addition to his outstanding research, Matthias has rendered exceptional service to the scientific community. From 1999 to 2005, he was a member of the Panel for the Collaborative Research Centers (SFBs) of the German Research Foundation (DFG). Matthias was the chairman of the thematic commission of the German Bunsen Society from 2008 to 2011. In the next 2 years (2011-2012), he was a member of the standing committee of the Bunsen Society. From 2012 to 2020, Matthias was an elected member of the DFG review board representing the subject area experimental and theoretical polymer physics. Matthias also serves the Scientific \& Advisory Board of the European School HERCULES. Furthermore, he has been an editor and editorial board member of several recognized journals devoted to research on polymers and colloids.

To his friends, colleagues, and co-workers, Matthias is not only known for his sharp intellect but also for his rhetoric abilities paired with a fine sense of humor. This allows him to get to the point quickly by using unambiguous comparisons. Insiders will know about similarities he has drawn between habits at universities and thermodynamic principles.

Dear Matthias, we, as well as the editors-in-chief and all the contributors, wish you the best in your future endeavors! The new phase of life will surely offer you creative freedom and new opportunities, which we know you will tackle wholeheartedly and with your contagious enthusiasm, which we all admire.

May 2020, Freiburg and Konstanz

Joachim Dzubiella and Alexander Wittemann

Funding Information Open Access funding provided by Projekt DEAL.

Open Access This article is licensed under a Creative Commons Attribution 4.0 International License, which permits use, sharing, adaptation, distribution and reproduction in any medium or format, as long as you give appropriate credit to the original author(s) and the source, provide a link to the Creative Commons licence, and indicate if changes were made. The images or other third party material in this article are included in the article's Creative Commons licence, unless indicated otherwise in a credit line to the material. If material is not included in the article's Creative Commons licence and your intended use is not permitted by statutory regulation or exceeds the permitted use, you will need to obtain permission directly from the copyright holder. To view a copy of this licence, visit http://creativecommons.org/licenses/by/4.0/.

Publisher's note Springer Nature remains neutral with regard to jurisdictional claims in published maps and institutional affiliations. 